\title{
A simple method for preserving environmental DNA in water samples at ambient temperature by addition of cationic surfactant
}

\author{
Hiroki Yamanaka ${ }^{1} \cdot$ Toshifumi Minamoto $^{2} \cdot$ Junichi Matsuura $^{3} \cdot$ Sho Sakurai $^{4}$. \\ Satsuki Tsuji ${ }^{4} \cdot$ Hiromu Motozawa $^{4} \cdot$ Masamichi Hongo $^{4} \cdot$ Yuki Sogo $^{4} \cdot$ \\ Naoki Kakimi $^{4} \cdot$ Iori Teramura $^{1} \cdot$ Masaki Sugita $^{1} \cdot$ Miki Baba $^{1} \cdot$ Akihiro Kondo $^{5}$
}

Received: 31 August 2016/Accepted: 31 October 2016/Published online: 19 November 2016

(c) The Author(s) 2016. This article is published with open access at Springerlink.com

\begin{abstract}
Environmental DNA (eDNA) analysis is a powerful tool within ecology for the study of the distribution or abundance of aquatic species, although the simplification of water sampling is required for enabling light and fast field sampling to expand further application of eDNA analysis. Here, certain candidate chemicals belonging to the group of cationic surfactants were examined for their effectiveness as preservatives for eDNA water samples by simply adding the chemicals to water samples to suppress the degradation of eDNA. The quaternary ammonium compound benzalkonium chloride (BAC) at a final concentration of $0.01 \%$ was effective to retain $92 \%$ of eDNA derived from the bluegill sunfish Lepomis macrochirus in an 8-h incubation test at ambient temperature, which assumed a transportation of water samples in 1-day field sampling during the daytime. Meanwhile, eDNA in water samples without BAC retained only $14 \%$ of the initial eDNA. Moreover, an additional
\end{abstract}

Handling Editor: Hideyuki Doi.

Hiroki Yamanaka

yamanaka@rins.ryukoku.ac.jp

1 Faculty of Science and Technology, Ryukoku University, 1-5 Yokotani, Seta Oe-cho, Otsu, Shiga 520-2194, Japan

2 Graduate School of Human Development and Environment, Kobe University, 3-11 Tsurukabuto, Nada-ku, Kobe 657-8501, Japan

3 Settsu Oil Mill Inc., 1-5-10 Chikkoshinmachi, Nishi-ku, Sakai, Osaka 592-8331, Japan

4 Graduate School of Science and Technology, Ryukoku University, 1-5 Yokotani, Seta Oe-cho, Otsu, Shiga 520-2194, Japan

5 Hiyoshi Corporation, 908 Kitanosho-cho, Omihachiman, Shiga 523-0806, Japan long-term incubation test (up to 10 days) revealed BACtreated samples retained $\sim 70$ and $50 \%$ of bluegill DNA compared to the initial amount after 1- and 10-day incubation at ambient temperature, respectively. Meanwhile, eDNA in naïve samples reduced to $20 \%$ after 1-day incubation and reached undetectable levels after 10 days. Up to now, many eDNA studies have adopted on-site filtration followed by filter fixation, which requires many pieces of equipment. Addition of BAC can protect eDNA in water samples with less effort and equipment resulting in an increase of measurement accuracy of the eDNA quantity and detection probability of rare species by preventing the disappearance of rare sequences in water samples.

Keywords eDNA - Degradation - Less equipment requirements $\cdot$ Macroorganism $\cdot$ Preservatives

\section{Introduction}

The biological monitoring of aquatic vertebrates by environmental DNA (eDNA) analysis is currently experiencing rapid expansion in multiple disciplines, such as rare species conservation (Rees et al. 2014; Fukumoto et al. 2015) and invasive species management (Ficetola et al. 2008; Jerde et al. 2011; Takahara et al. 2013). In most cases, the species-specific detection of eDNA shed by a target species into surrounding water is commonly applied to reveal the macroorganism distribution (Goldberg et al. 2011; Keskin 2014; Yamanaka and Minamoto 2016) and in some cases to estimate the biomass or abundance (Takahara et al. 2012; Klymus et al. 2015; Lacoursière-Roussel et al. 2016). Recently, a metabarcoding technique has been implemented for eDNA analysis using universal primers and a next-generation sequencer to simultaneously determine the species composition (Thomsen et al. 
2012; Kelly et al. 2014; Miya et al. 2015), thereby enabling an extensive high-throughput analysis of faunas from multiple target sites. Therefore, the establishment of a simple sampling method is required to leverage the potential of eDNA analysis by collecting samples from a number of sampling sites, which cannot be covered by other conventional monitoring methods, such as direct capture of organisms.

Improved preservation of the initial state of an eDNA sample at the time of sampling would increase the reliability of analysis results in terms of the number of species detected by metabarcoding or the biomass estimated by the quantification of eDNA from a target species. This is because the eDNA sample in its initial state is most likely the best reflector of the fauna at the time of sampling. eDNA is suggested to degrade rapidly in water, with the rate varying among species (Thomsen et al. 2012; Maruyama et al. 2014; Pilliod et al. 2014). Temperature-dependent variation has also been reported, with decreased degradation rates at lower temperatures (Eichmiller et al. 2016). This problem hampers the comparison of the eDNA concentration among sampling sites or among species because of the time lag of sampling between sites or the species-specific degradation rate of eDNA. Consequently, eDNA degradation in water after sampling might reduce the quality of eDNA analysis.

In previous studies, various eDNA sample preservation techniques, such as cooling the water samples in a cool box (Takahara et al. 2012; Eichmiller et al. 2014; LacoursièreRoussel et al. 2016), freezing the water samples (Takahara et al. 2015) and on-ice preservation/ethanol fixation/immersion in lysis buffers of obtained filter samples (Goldberg et al. 2011; Takahara et al. 2012; Renshaw et al. 2015; Minamoto et al. 2016), have been followed to decelerate the degradation rate of eDNA. However, on-site filtration requires a sophisticated system setup, and cooling or freezing of water and filter samples requires a cool box or portable freezer, resulting in increased equipment requirements for field sampling and an increased contamination risk. The requirement of numerous pieces of equipment hinders the expansion of the sampling area by requiring multiple survey teams or citizen scientists. In addition, cooling the water sample is insufficient to avoid sample degradation as eDNA degrades even at $4-5{ }^{\circ} \mathrm{C}$ (Pilliod et al. 2014; Eichmiller et al. 2016), whereas freezing the water samples might inhibit polymerase chain reactions (PCRs) (Takahara et al. 2015). Therefore, developing a novel simple method of preserving water samples for eDNA analysis using less equipment and a simpler on-site procedure is essential. Ideally, developing a preservative that is efficient even at ambient temperatures and merely requires its addition to water samples would be the optimal solution.

We examined certain chemical agents, categorised as cationic surfactants, for their potential as preservatives.
These chemicals, commonly used as antiseptic drugs in medical and sanitary fields, were used in the present study to suppress eDNA degradation by microorganisms. The efficiency of each preservative was determined in terms of its ability to decelerate/halt the reduction of the eDNA concentration depending on the incubation duration of sample water at ambient temperature after sampling.

\section{Materials and methods}

\section{Preservatives tested}

Three cationic surfactants were selected as candidate preservatives. Cationic surfactants are adsorbed on the negatively charged bacterial cell membrane because of their positive surface electric charge. This produces an antiseptic effect, resulting in the disruption of normal cellular function (Ziani et al. 2011). The three candidates varied in their number of benzene rings.

\section{Benzalkonium chloride (BAC)}

Benzalkonium chloride (BAC), also known as alkyldimethylbenzylammonium chloride, is the cationic surfactant most frequently used in ophthalmic solutions as a preservative (Fig. 1a). In the present study, we used 10\% Takeclean A-ST (Settsu Oil Mill Inc., Sakai, Japan) as the BAC source.

(a)<smiles>[R][N+](C)(C)Cc1ccccc1</smiles>

(b)

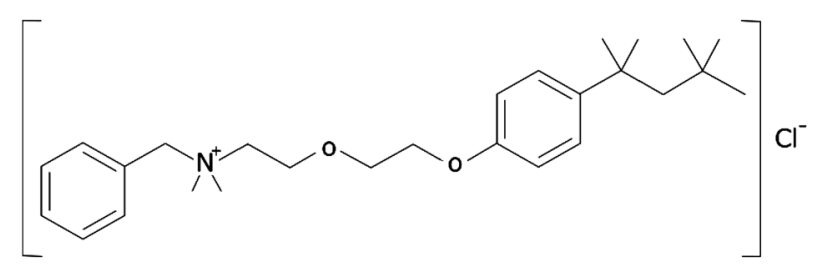

(c)

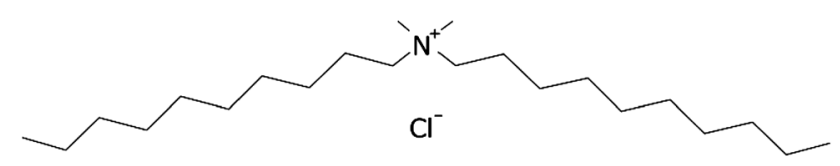

Fig. 1 Chemical structures of candidate cationic surfactants examined in the present study: a benzalkonium chloride (BAC), $\mathrm{R}=-$ $\mathrm{C}_{8} \mathrm{H}_{17}-\mathrm{C}_{18} \mathrm{H}_{37}$, b benzethonium chloride (BEC) and $\mathbf{c}$ didecyldimethylammonium chloride (DDAC) 


\section{Benzethonium chloride (BEC)}

BEC, also known as hyamine, is a synthetic quaternary ammonium salt (Fig. 1b). It is used as an ingredient in medicaments, deodorants and mouthwashes and also to disinfect equipment in food processing and pharmaceutical industries, during surgery and as a preservative. In the present study, we used $10 \%$ hyamine solution (Daiichi Sankyo Espha Co., Ltd., Tokyo, Japan) as the BEC source.

\section{Didecyldimethylammonium chloride (DDAC)}

DDAC, a quaternary ammonium compound, is antiseptic and is used in many biocidal applications as a disinfectant (Fig. 1c). In the present study, we used $7 \%$ Catiogen DDM-PG (DKS Co., Ltd., Kyoto, Japan) as the DDAC source.

\section{Experiment 1: short-term test using BAC}

\section{Treatments}

Ex1-On-ice-Initial No preservative was added to the water samples. Samples were immediately filtered on site, and filter samples were transported to the laboratory on ice. They were incubated on ice for $6 \mathrm{~h}\left(3.0 \pm 0.1^{\circ} \mathrm{C}\right)$ until filtering of Ex1-BAC0.01 samples was complete.

Exl-BAC0.01 BAC at a final concentration of $0.01 \%$ was added to samples on site immediately after water sampling. The samples were transported to the laboratory and filtered after incubation at ambient temperature $\left(25.3 \pm 0.1{ }^{\circ} \mathrm{C}\right)$ for $6 \mathrm{~h}$ after completing the filtration of the Ex1-On-iceInitial samples.

An incubation time of $6 \mathrm{~h}$ was set by assuming a 1-day field trip to collect water samples during the daytime. Five replicates of water samples in each treatment were sampled. Each treatment contained a negative control sample comprising 500-ml ultrapure water sourced from the laboratory. The negative control samples were analysed along with the experimental samples to assess unintended contamination during the transportation, incubation, filtration and extraction steps. In all of the following experiments, the negative control samples were included and analysed in the same manner.

\section{Water sampling}

Water samples were obtained at $15: 40$ on 18 September 2015 from the Wani River (35.154509 N, 135.922484 E), a tributary of Lake Biwa, Japan, located at the southwestern shore of the north basin of the lake. The fish fauna of this river include many migratory fish species including ayu sweetfish Plecoglossus altivelis (Plecoglossidae, Osmeriformes), swimming up to the river from Lake Biwa. Each water sample was collected directly from the water surface by submerging a plastic container (volume, $\sim 101$; made of polyethylene) and divided into two containers (3 1 each; made of polyethylene). One container was assigned to Ex1On-ice-Initial and the other to Ex1-BAC0.01, and 3-ml of $10 \% \mathrm{BAC}$ at a final concentration of $0.01 \%$ was added to the latter container. Using a beaker with a handle, $500 \mathrm{ml}$ water from each container was dispensed into each of the five different plastic bags (DP16-TN1000; Yanagi, Nagoya, Japan; made of polyethylene), and the bags were subsequently sealed. The five bags of Ex1-On-ice-Initial were immediately filtered on site according to the method described in the next paragraph. Filter samples were stored on ice in a cool box. The five bags of Ex1-BAC0.01 were subjected to 6-h incubation at ambient temperature in a cardboard box and transported to a laboratory during the incubation. Using the hand sensors HI 98128 pHep 5, HI 98312 DiST 6 and HI 98312 DiST 6 (HANNA Instruments, Woonsocket, RI, USA), the $\mathrm{pH}$, electrical conductivity (EC) and temperature of the water at the sampling site were measured to be $7.89,0.26 \mathrm{mS} / \mathrm{cm}$ and $25.0{ }^{\circ} \mathrm{C}$, respectively. The temperature conditions in the cool box used for the Ex1-On-ice-Initial filter samples and in the cardboard box for Ex1-BAC0.01 were measured using temperature loggers (UA-001-64; Onset Computer Corp., Bourne, MA, USA). All plastic containers used for water sampling were sterilised before use using $10 \%$ bleach solution. This decontamination procedure was adopted at water sampling in all of the following experiments.

\section{Filtration of water samples}

The five Ex1-On-ice-Initial water samples were filtered on site immediately after sampling using GF/F glass fiber filters (diameter $=47 \mathrm{~mm}$, nominal pore size $=0.7 \mu \mathrm{m}$; GE Healthcare), filter holders (PP-47, ADVANTEC, Tokyo, Japan) and an aspirator pump (DP0105-X1-0001, Nitto Kohki, Tokyo, Japan) powered by a $12-\mathrm{V}$ car battery. Each sample bag containing water was connected to the filter holder and filtered. The five Ex1-BAC0.01 water samples were subjected to incubation at ambient temperature under darkness in a cardboard box for $6 \mathrm{~h}$, following which they were filtered in the same manner as the Ex1On-ice-Initial samples. In all treatments, $500 \mathrm{ml}$ water from each bag was filtered. For each sample, the filter disc was removed from the filter holder, folded inward, wrapped in aluminium foil and placed in a plastic bag using forceps. All filters including Ex1-On-ice-Initial and Ex1-BAC0.01 filter samples were stored in a freezer at $-20{ }^{\circ} \mathrm{C}$ immediately after filtration for the Ex1-BAC0.01 samples until the subsequent DNA extraction. All equipment used for 
filtration, including filter holders and forceps, were sterilised before use using $10 \%$ bleach solution.

\section{DNA extraction}

Filter samples were subjected to DNA extraction following the method suggested by Miya et al. (2015). Briefly, each filter was rolled into a cylindrical shape using sterile forceps and placed into a spin column (EZ-10 SpinColumn \& Collection Tube; Bio Basic Inc., Ontario, Canada). The silica membranes of the columns were removed before use. The columns were centrifuged at $6000 \times g$ for $1 \mathrm{~min}$ and excess water on the filter recovered as the filtrate was discarded. Two hundred microlitres ultrapure water, $100 \mu \mathrm{l}$ buffer $\mathrm{AL}$ and $10 \mu \mathrm{l}$ proteinase $\mathrm{K}$ were dispensed onto the filter, and the spin columns were then incubated at $56{ }^{\circ} \mathrm{C}$ for $15 \mathrm{~min}$. The buffer AL and proteinase $\mathrm{K}$ from a DNA extraction kit (DNeasy Blood and Tissue Kit; Qiagen, Hilden, Germany) were used for this step. The column was then centrifuged at $6000 \times g$ for $1 \mathrm{~min}$, and the filtrate was

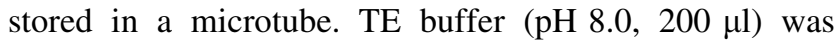
added onto the filter and centrifuged at $6000 \times g$ for $1 \mathrm{~min}$ to recover the remaining DNA on the filter after 1-min incubation at room temperature. The first filtrate was stored in a microtube, whereas the second filtrate comprising TE buffer was mixed in a 2-ml collection tube. After adding $200 \mu \mathrm{l}$ buffer AL and $600 \mu \mathrm{l}$ ethanol to the 2 -ml collection tube, the mixture of $\sim 1210 \mu \mathrm{l}$ was subjected to DNA purification using a DNeasy spin column, according to the manufacturer's instructions. During the final elution step, DNA trapped on the silica membrane of the spin column was eluted with $100 \mu \mathrm{l}$ buffer AE.

\section{Real-time polymerase chain reaction (PCR) assay}

The DNA of the ayu in each sample was quantified using StepOnePlus ${ }^{\circledR}$ Real-Time PCR System (Life Technologies, Foster City, CA, USA) to determine DNA degradation. The sequences of the forward and reverse primers and a probe for the cytochrome $b$ gene of ayu were as follows: Paa-CyB-Forward, 5'-CCTAGTCTCCCTGGCTTTATTCTCT-3'; PaaCyB-Reverse, $5^{\prime}$-GTAGAATGGCGTAGGCGAAAA- $3^{\prime}$ and Paa-CyB-Probe, 5'-FAM-ACTTCACGGCAGCCAACCCC C-TAMRA-3' developed by Yamanaka and Minamoto (2016). PCR was conducted in triplicate in a $15-\mu$ l reaction mixture comprising $900 \mathrm{nM}$ of each of the primers and $125 \mathrm{nM}$ of the probe at final concentrations in $1 \times$ Gene Expression Master Mix (Life Technologies) with $1 \mu$ template DNA. Quantification standards adjusted to the copy numbers of $3 \times 10^{1}-$ $3 \times 10^{4}$ copies per reaction were adopted for all real-time PCR assays. The quantification standards originated from a dilution series of a plasmid, which included an artificially synthesised
DNA of target sequences. In all real-time PCR assays, negative controls in triplicate were adopted to assess the occurrence of unintended cross contamination using ultrapure water instead of the DNA template. The thermal conditions for PCR were 2 min at $50{ }^{\circ} \mathrm{C}$ and $10 \mathrm{~min}$ at $95{ }^{\circ} \mathrm{C}$, followed by 55 cycles of $15 \mathrm{~s}$ at $95^{\circ} \mathrm{C}$ and $60 \mathrm{~s}$ at $60^{\circ} \mathrm{C}$. The $\mathrm{R}^{2}$ values of the standard curve for all qPCR experiments exceeded 0.98 .

\section{Experiment 2: test using three cationic surfactants}

\section{Treatments}

Ex2-Initial No preservative was added to the water sample. Samples were immediately filtered on site and stored for $8 \mathrm{~h}$ in a portable $-18{ }^{\circ} \mathrm{C}$ freezer (MR040F; Sawafuji Electric Co., Ltd., Ota, Japan) powered by a 12-V car battery until the other samples had been filtered. In the present experiment, on-site filtration followed by filter sample preservation in a portable freezer was adopted to prepare the initial sample as we found considerable reduction of eDNA in Ex1-On-ice-Initial samples, even though they were filtered on site and transported to the laboratory on ice (see "Results").

Ex2-Naïve No preservative was added to water samples. Samples were transported from the sampling site to the laboratory and filtered after incubation at ambient temperature $\left(22.5 \pm 0.2^{\circ} \mathrm{C}\right)$ for $8 \mathrm{~h}$ after the filtration of Ex2Initial samples.

Ex2-BAC0.1, 0.01, 0.001 BAC at final concentrations of $0.1,0.01$ and $0.001 \%$ was added on site immediately after water sampling. Samples were transported to the laboratory in the same manner as Ex2-Naïve and filtered.

Ex2-BEC0.1, 0.01, 0.001 BEC at final concentrations of $0.1,0.01$ and $0.001 \%$ was immediately added after water sampling on site. Samples were transported in the same manner as Ex2-Naïve and filtered.

Ex2-DDAC0.07, 0.007, 0.0007 DDAC at final concentrations of $0.07,0.007$ and $0.0007 \%$ was added on site immediately after water sampling. Samples were transported and filtered in the same manner as Ex2-Naïve.

Ex2-SH0.1, 0.01, 0.001 Sodium hypochlorite $(\mathrm{SH})$ at final concentrations of $0.1,0.01$ and $0.001 \%$ was added on site immediately after water sampling. Samples were transported and filtered in the same manner as Ex2-Naïve. $\mathrm{SH}$ is an oxidising agent and an ingredient in bleach, which can act as a powerful antiseptic chemical in a different way from BAC, BEC and DDAC. SH degrades DNA molecules and therefore has been used for decontaminating DNA in a 
number of eDNA studies. In the present experiment, $\mathrm{SH}$ was used as a control.

An incubation time of $8 \mathrm{~h}$ was set by carrying out a 1-day field trip to collect water samples during daytime. Water samples in each treatment were sampled in triplicate. Each treatment contained a negative control water sample comprising 500-ml ultrapure water sourced from the laboratory. Negative control samples were analysed along with the other experimental samples to assess unintended contamination during the transportation, incubation, filtration and extraction steps.

\section{Water sampling}

Water samples were obtained from a pond (TsukinowaOike pond, Otsu, Japan; 34.981480 N, 135.945857 E) at 11:15 on 15 October 2015. Each water sample was obtained directly from the water surface by submerging a plastic container (volume, 301 ; made of polyethylene). Using a beaker with a handle, $500 \mathrm{ml}$ of water was dispensed into each of the 42 plastic bags (DP16-TN1000), and the bags were subsequently sealed. The 500-ml water samples were randomly assigned to the Ex2-Initial, Naïve, BAC, BEC, DDAC and SC treatments. Ex2-Initial samples were immediately filtered on site using the same method as in Experiment 1. Five per cent BAC, 5\% BEC, 3.5\% DDAC and 5\% SH were added to all bags assigned to Ex2BAC, BEC, DDAC and SC, respectively, and adjusting to the three levels of final concentrations described in the previous paragraph. All bags except those of Ex2-Initial were subjected to 8-h incubation at ambient temperature in a cardboard box and were subsequently transported to the laboratory. Water at the sampling site was measured to have a $\mathrm{pH}$ of $8.57, \mathrm{EC}$ of $0.08 \mathrm{mS} / \mathrm{cm}$ and temperature of $21.3{ }^{\circ} \mathrm{C}$ using the same hand sensors as in Experiment 1. The temperature condition in the cardboard box for incubation was measured using a temperature logger (UA-00164). Equipment for water sampling was sterilised in the same manner as in Experiment 1.

Three Ex2-Initial water samples were filtered on site, whereas the remaining samples in triplicate, respectively, were filtered after 8-h incubation using the method described in Experiment 1. All filter samples were stored in a freezer at $-20{ }^{\circ} \mathrm{C}$ until the subsequent DNA extraction. All equipment used for filtration, including filter holders and forceps, was sterilised before use using $10 \%$ bleach solution. DNA was extracted from filter samples using the method described in Experiment 1. The PCR assay was also conducted using the method described in Experiment 1; however, the target species was changed to bluegill sunfish Lepomis macrochirus (Centrarchidae, Perciformes) inhabiting the pond. The primer and probe sequences were Bluegill_CytB_F 5'-GCCTAGCAACCCAGATTTTAA
CA-3', Bluegill_CytB_R 5'-ACGTCCCGGCAGATGTG T-3' and Bluegill_CytB_probe 5'-FAM-CGACATCGCAA CTGCCTTCTCTTCAGT-BHQ- ${ }^{\prime}$, as suggested by Takahara et al. (2013). Moreover, the volume of DNA template per PCR reaction was changed to $2 \mu$ in a $15-\mu l$ PCR mixture. The $\mathrm{R}^{2}$ values of the standard curve for all qPCR experiments exceeded 0.98 .

\section{Experiment 3: long-term test using BAC}

\section{Treatments}

Ex3-Nä̈ve-Od, -1d, -3d, -5d, -10d No preservative was added to water samples. Ex3-Naïve-Od samples were immediately filtered on site and frozen in a portable freezer at $-18{ }^{\circ} \mathrm{C}$ (MR040F) and transported to the laboratory. Ex3-Naïve-1d, -3d, -5d and-10d samples were transported to the laboratory without filtration and filtered after incubation at ambient temperature $\left(21.4 \pm 1.2^{\circ} \mathrm{C}\right)$ for $1,3,5$ and 10 days after the filtration of Ex3-Naïve-0d initial samples.

Ex3-BAC0.01-0d, -1d, -3d, -5d, -10d BAC at a final concentration of $0.01 \%$ was added on site immediately after water sampling. Ex3-BAC0.01-0d samples were immediately filtered on site and frozen in a portable freezer $-18{ }^{\circ} \mathrm{C}$ (MR040F). Ex3-BAC0.01-1d, -3d and -5d, -10d samples were transported to the laboratory and analysed in the same manner as the corresponding Ex3-Naïve samples.

The incubation duration, i.e., up to 10 days, was set to cover the whole degradation process of naïve samples to reach an undetectable level to illustrate the long-term effectiveness of BAC. Water samples in each treatment were sampled in triplicate. Each treatment contained a negative control water sample comprising $500 \mathrm{ml}$ ultrapure water sourced from the laboratory. Negative control samples were analysed along with the other experimental samples to assess unintended contamination during transportation, incubation, filtration and extraction steps.

\section{Water sampling}

Water samples were obtained from the same site as in Experiment 2 at 9:05 on 9 December 2015. Water samples were obtained directly from the water surface by submerging a plastic container (volume, $\sim 201$; made of polyethylene). Using a beaker with a handle, $500 \mathrm{ml}$ water was decanted into each of the 30 plastic bags (DP16TN1000), and the bags were subsequently sealed. Each bag was randomly assigned to each control. Ten percent BAC was added at a final concentration of $0.01 \%$ to all bags assigned to Ex3-BAC0.01. All bags assigned to Ex3Naïve-0d and Ex3-BAC0.01-0d were immediately filtered 
on site using the same method as in Experiment 1. All of the remaining bags were subjected to incubation up to 10 days at ambient temperature in a cardboard box. The samples were transferred to a laboratory during the incubation. Water quality variables at the sampling site were measured at a $\mathrm{pH}$ of $7.33, \mathrm{EC}$ of $0.08 \mathrm{mS} / \mathrm{cm}$ and water temperature of $11.1^{\circ} \mathrm{C}$ using the same hand sensors as in Experiment 1 . The temperature condition in the cardboard box for incubation was measured using a temperature logger (UA-001-64). Equipment for water sampling was sterilised in the same manner as in Experiment 1.

\section{Filtration of water samples}

Water samples assigned to Ex3-Naïve-0d and Ex3BAC0.01-0d were filtered on site, whereas the remaining samples were filtered after a series of incubation times (1, 3, 5 and 10 days) using the same method as in Experiment 1. All filter samples were stored in a freezer at $-20{ }^{\circ} \mathrm{C}$ until the subsequent DNA extraction. All equipment used for filtration, including filter holders and forceps, was sterilised before use with $10 \%$ bleach solution.

DNA was extracted from filter samples using the method in Experiment 1. The PCR assay on bluegill was conducted following the method used in Experiment 2 . The $\mathrm{R}^{2}$ values of the standard curve for all qPCR experiments exceeded 0.98 .

\section{Statistical analysis}

DNA concentrations were calculated as DNA copies per filtered water volume $(500 \mathrm{ml})$ based on real-time PCR results and subjected to statistical analyses. All statistical analyses were performed using $R$ version 3.0.2 software ( $R$ Core Team 2013). The average DNA concentration was compared among treatments using a $t$ test or one-way analysis of variance (ANOVA) followed by a post hoc test. In Experiment 3, the $\mathrm{lm}$ function of $\mathrm{R}$ was used to determine the difference in the concentration of eDNA (log-transformed before analysis) between naïve and BAC-added controls using the presence/absence of BAC and the incubation days as explanatory variables. In the present analysis, the average eDNA concentration in triplicate samples in each treatment was used; however, replicates without positive result were excluded from the calculation of the averages. Alpha, or the significance level, was set to 0.05 in all analyses.

\section{Results}

\section{Experiment 1}

Experiment 1 determined the deceleration effect of BAC on ayu DNA degradation within $6 \mathrm{~h}$ of incubation at ambient temperature. Ex1-On-ice-Initial samples contained less DNA than those in Ex1-BAC0.01 samples $(P<0.001$; $65,772.7 \pm 23,616$ and 456,326.4 $\pm 43,240.6$ copies/ $500 \mathrm{ml}$, respectively; Fig. 2). The latter contained a 6.94 times higher concentration of ayu DNA. Ex1-On-ice-Initial samples were filtered on site, and filter samples were transported on ice, although the DNA concentration was lower than that of Ex1-BAC0.01 samples, which were incubated at ambient temperature for $6 \mathrm{~h}$ before filtration.

\section{Experiment 2}

eDNA degradation was confirmed in Experiment 1, even in the cases where the water samples were filtered on site, and the filter samples were transported to the laboratory on ice. Therefore, in Experiment 2, initial samples were filtered on site, and the filter samples were transported to the laboratory in a frozen state using a portable freezer. Each of the three candidate preservatives was used at three different concentrations for treatments. The DNA concentrations in most of the treatments using addition of preservatives other than SH were higher than those of Ex2-Naïve samples after 8 -h incubation at ambient temperature $(P<0.05$ in all combinations; Fig. 3). A significant difference was not found only in the combination of Ex2-Naïve and Ex2BEC0.1 $(P=0.104)$. In comparison with Ex2-Initial samples, significant reductions in the DNA concentration in all treatments with preservatives other than $\mathrm{SH}$ were not observed, regardless of their concentrations $(P \geq 0.05$ in

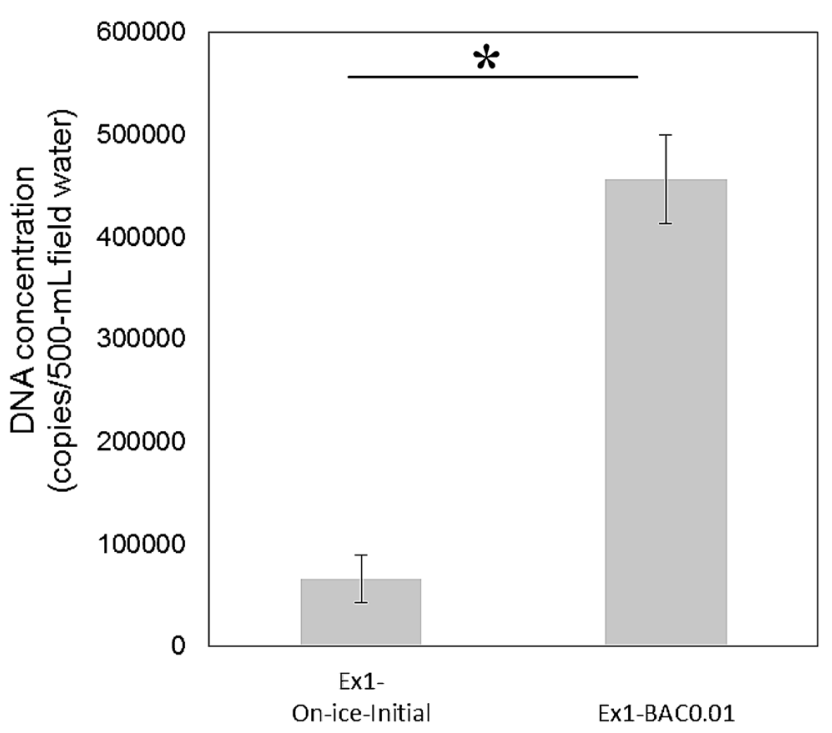

Fig. 2 DNA concentrations of the ayu sweetfish Plecoglossus altivelis determined in Experiment 1. Ex1-BAC0.01 was treated with benzalkonium chloride (BAC). See "Materials and methods" for treatment details. Asterisk indicates a significant difference between the groups. Error bars show the standard deviation of each group $(n=5$, each $)$ 
all combinations; Fig. 3). Although the differences were not significant, slight reductions in the DNA concentrations were observed in all treatments with cationic surfactant preservatives (Fig. 3). In Ex2-BEC0.1, the average DNA concentration in the control was determined to be $56 \%$ of that of Ex2-Initial. Significant differences in DNA concentrations were detected between Ex2-Initial and Ex2Naïve samples $(P<0.001)$, namely $6409.6 \pm 1067.4$ and $926.9 \pm 344.1$ copies $/ 500 \mathrm{ml}$, respectively. In controls using the same preservative, the retention rates of DNA were not different among treatments, regardless of preservative concentrations ( $P \geq 0.05$ in all combinations). DNA was not detected at all in any treatments with $\mathrm{SH}$ addition.

\section{Experiment 3}

In Experiment 3, only BAC was used as a preservative at $0.01 \%$ concentration because of the resulting relatively high retention rate of DNA in Experiment 2 ( 92.1\%), although the difference was not significant among three preservatives. No significant difference in the DNA concentrations between Ex3-Naïve-0d and Ex3-BAC0.01-0d was observed $(P>0.05)$. The linear model $(\mathrm{lm})$ analysis revealed significant effects of incubation days $(P<0.001)$ on the concentration of eDNA (Fig. 4). Although the presence/absence of BAC did not have a significant effect $(P>0.05)$, it affected the eDNA concentration through an interaction effect with incubation days $(P<0.001)$. An ANOVA test revealed that the DNA concentrations in all

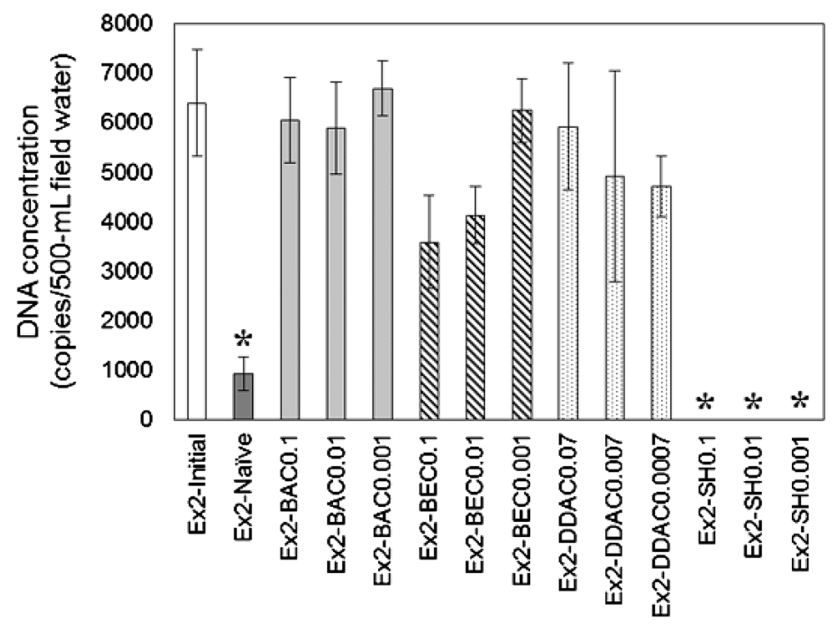

Fig. 3 DNA concentrations of the bluegill sunfish Lepomis macrochirus determined in Experiment 2 using various preservatives and different concentrations after 8-h incuation at room temperature: $B A C$ benzalkonium chloride, $B E C$ benzethonium chloride, $D D A C$ didecyldimethylammonium chloride, $S H$ sodium hypochlorite. See "Materials and methods" for treatment details. Asterisk indicates a significant difference from the Ex2-Initial. Error bars show a standard deviation of each group $(n=3$, each)

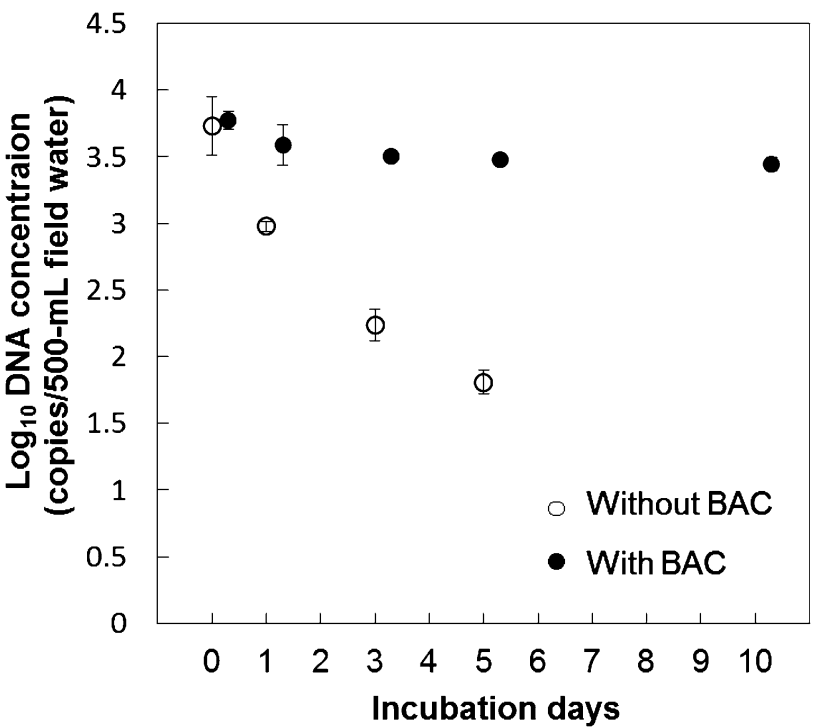

Fig. 4 Time-dependent decrement of DNA concentrations of the bluegill sunfish Lepomis macrochirus in benzalkonium chloride (BAC)-treated and naïve water samples determined in Experiment 3. DNA concentrations are shown as their common logarithm. See "Materials and methods" for treatment details. Error bars show the standard deviation of each group $(n=3$, each)

water samples without a preservative (Ex3-Naïve-1d, -3d, $5 \mathrm{~d},-10 \mathrm{~d})$ were different from those in Ex3-Naïve-Od samples regardless of the incubation days $(P<0.05$ in all combinations; Fig. 4). The reduction rates were 83.6, 97.0, 99.3 and $100 \%$, in Ex3-Naïve-1d, $-3 \mathrm{~d},-5 \mathrm{~d}$ and $-10 \mathrm{~d}$, respectively (Fig. 4). On the other hand, no significant reduction in DNA concentrations in BAC controls (Ex3BAC0.01-1d, -3d, -5d, -10d) was observed in comparison with those in Ex3-Naïve-Od samples $(P>0.05$ in all combinations) even after 10-day incubation (Ex3BAC0.01-10d). Although the reductions in DNA concentrations in the BAC controls were not significant, their reduction rates were calculated as $30.3,45.3,48.5$ and $52.3 \%$ in Ex3-BAC0.01-1d, $-3 \mathrm{~d},-5 \mathrm{~d}$ and $-10 \mathrm{~d}$, respectively (Fig. 4).

In all experiments, no occurrence of DNA cross contamination among samples during filtration, transportation and the subsequent molecular analysis was observed, as indicated by negative results for all of the negative controls, including PCR-negative controls.

\section{Discussion}

The present study suggested that water samples for eDNA analyses can be preserved for a considerable duration at ambient temperature under the effect of the preservatives described here. On average, BAC appeared to be the most effective; however, all the remaining preservatives 
belonging to the group of cationic surfactants were also effective in halting or significantly decelerating the degradation rate of DNA in water samples, as confirmed by the results of Experiment 2. In Experiment 3, which focused on BAC, a significant reduction in DNA concentration was not observed in treatments with BAC addition at $0.01 \%$ concentration even after 10-day incubation at ambient temperature $\left(\sim 21{ }^{\circ} \mathrm{C}\right)$, and the retention rate of DNA was determined to be $\sim 50 \%$. This result is remarkable in comparison with the failure of DNA detection in a control without BAC after 10-day incubation. Even after 1-day incubation, approximately $80 \%$ of DNA was degraded in the control without BAC. Based on these results, the effectiveness of BAC as an eDNA preservative can be considered exceptional. Using these cationic surfactants as eDNA preservatives, the degradation rate of DNA in a sample water could be reduced to $\sim 10$ and $50 \%$ within 8-h and 10-day incubations, respectively, at an ambient temperature. Cationic surfactants are adsorbed onto the bacterial surface because of their positively charged cell membrane, following which the normal function of the bacterial cells is considerably disturbed (Ziani et al. 2011). Moreover, it may influence DNase to reduce its degrading effect on DNA, thereby contributing to DNA preservation. The preservation methods of eDNA water samples shown in the present study can contribute to increasing the accuracy of eDNA quantification and to reducing false-negative results in case of detecting rare species or invasive species by reducing the probability of the disappearance of rare sequences in a water sample during transportation. In the present study, we focused on a freshwater habitat, although we also confirmed the effectiveness of BAC as a preservative for eDNA in saltwater by targeting blackhead seabream Acanthopagrus schlegelii (Bleeker, 1854; Sparidae, Perciformes). Twenty-four-hour incubation of sample water with BAC at ambient temperature did not produce a significant difference in the DNA concentration from the initial value (Minamoto et al., unpublished). The effectiveness of the eDNA preservatives is remarkable, although further detailed examinations are merited, e.g., on their effect as a PCR inhibitor, as there was a slight reduction of the eDNA concentration in samples to which a higher concentration of BEC was added in Experiment 3 (Fig. 3). In addition, future studies should clarify whether there are biases in the effectiveness of these preservatives among target species or among different biomasses.

In Experiment 1, a considerable reduction in the DNA concentration in the initial sample (Ex1-On-ice-Initial) without preservatives was observed, probably because of the DNA degradation during transportation, even when the water sample was filtered on site and filter samples were transported to the laboratory on ice. Moreover, in our preliminary experiment in which a water sample was transported to the laboratory in a cool box within $7.5 \mathrm{~h}$ and filtered, the resulting DNA concentration in the sample was considerably lower than that of a 3-day incubated sample that was treated with $0.01 \% \mathrm{BAC}$ at ambient temperature (Yamanaka et al. unpublished). These results suggest that the DNA concentrations measured in previous studies, which were affected by the method of sample transportation used, such as water transportation on ice (e.g. Takahara et al. 2012; Eichmiller et al. 2014; LacoursièreRoussel et al. 2016) or on-site filtration and transportation of filter samples on ice (Takahara et al. 2012), might not reflect the actual DNA concentration at the sampling time because of DNA degradation during sample transportation. Pilliod et al. (2014) noted a $38 \%$ reduction in the eDNA concentration of the Idaho giant salamander Dicamptodon aterrimus in 2 days, which was incubated at $4{ }^{\circ} \mathrm{C}$, although the detection rate appeared to be unaffected according to the PCR assay. This may cause difficulties in the eDNA quantification in studies where the concentration is used to estimate the biomass or abundance of the target species, particularly when water samples are collected from multiple sites because of the difference in the transportation time of water/filter samples among the sites. In Experiment 3 , on-site filtration followed by filter preservation in a portable freezer at $-18{ }^{\circ} \mathrm{C}$ was adopted to prepare the initial sample (Ex3-Naïve-0d). This more careful sample treatment resulted in the statistical equality of the average DNA concentrations between the initial sample and the BAC-treated sample, which was also filtered on site and preserved in the same freezer (Ex3-BAC0.01-0d). Taken together, it appears that the DNA concentration measured by the following two methods will provide the best estimate of the actual initial DNA concentration in the field water: (1) on-site filtration followed by filter preservation under a freezing temperature (or followed by preservation with ethanol or other preservatives instead, e.g. Goldberg et al. 2011, Renshaw et al. 2015) or (2) on-site addition of a preservative. In any case, only halting DNA degradation using the appropriate methods is required to obtain the best estimate of the DNA concentration as degradation begins immediately after water sampling. Further, comparing the two methods based on the amount of equipment required for field work, the method using a preservative is simpler.

In the present study, we focused on the DNA concentration of a specific species and confirmed the effectiveness of cationic surfactants as eDNA preservatives. We did not test the effectiveness to preserve eDNA samples for metabarcoding analysis, although the method we present here is likely to be effective for that as well because the deactivation of microorganisms will result in whole eDNA preservation in the water sample. However, further studies verifying the use of these preservatives in metabarcoding 
studies and in various water qualities are required. The adoption of eDNA analysis reduces the considerable amount of effort required in field work, thereby enabling biological monitoring at a very large scale. Similar to the Ocean Sampling Day (https://www.microb3.eu/myosd) initiative, the future involvement of citizen scientists in biological monitoring programs is inevitable to facilitate nation-wide, continent-wide or ocean-wide surveys. The statistical equivalence of the eDNA concentration between the initial sample and 8-h incubated samples in Experiment 2 suggests that usage of these preservatives can assure the strict measurement of the eDNA concentration without an on-site filtration protocol in daily field surveys. The simplification of eDNA sampling would accelerate the expansion of further applications of eDNA analysis in various studies.

Acknowledgements This work was supported by a Grant-in-Aid for the new technology development project of small and medium enterprises of Shiga Prefecture and partly supported by the Ryukoku University Technology Fund to HY. JM is an employee of Settsu Oil Mill, Inc., and AK is an employee of Hiyoshi Corp.

Open Access This article is distributed under the terms of the Creative Commons Attribution 4.0 International License (http://crea tivecommons.org/licenses/by/4.0/), which permits unrestricted use, distribution, and reproduction in any medium, provided you give appropriate credit to the original author(s) and the source, provide a link to the Creative Commons license, and indicate if changes were made.

\section{References}

Core Team R (2013) R: A language and environment for statistical computing. R Foundation for Statistical Computing, Vienna

Eichmiller J, Bajer PG, Sorensen PW (2014) The relationship between the distribution of common carp and their environmental DNA in a small lake. PLoS One 9:e112611. doi:10.1371/ journal.pone. 0112611

Eichmiller J, Best SE, Sorensen PW (2016) Effects of temperature and trophic state on degradation of environmental DNA in lake water. Envir Sci Tech 50:1859-1867. doi:10.1021/acs.est. 5 b05672

Ficetola GF, Miaud C, Pompanon F, Taberlet P (2008) Species detection using environmental DNA from water samples. Biol Lett 4:423-425. doi:10.1098/rsbl.2008.0118

Fukumoto S, Ushimaru A, Minamoto T (2015) A basin-scale application of environmental DNA assessment for rare endemic species and closely related exotic species in rivers: a case study of giant salamanders in Japan. J Appl Ecol 52:358-365. doi:10. 1111/1365-2664.12392

Goldberg CS, Pilliod DS, Arkle RS, Waits LP (2011) Molecular detection of vertebrates in stream water: a demonstration using Rocky Mountain tailed frogs and Idaho giant salamanders. PLoS One 6:e22746

Jerde CL, Mahon AL, Chadderton WL, Lodge DM (2011) "Sightunseen" detection of rare aquatic species using environmental DNA. Conserv Lett 4:150-157. doi:10.1111/j.1755-263X.2010. 00158.x
Kelly RP, Port JA, Yamahara KM, Crowder LB (2014) Using environmental DNA to census marine fishes in a large mesocosm. PLoS One 9:e86175. doi:10.1371/journal.pone.0086175

Keskin E (2014) Detection of invasive freshwater fish species using environmental DNA survey. Biochem Systemat Ecol 56:68-74. doi:10.1371/journal.pone.0022746

Klymus KE, Richter CA, Chapman DC, Paukert C (2015) Quantification of eDNA shedding rates from invasive bighead carp Hypophthalmichthys nobilis and silver carp Hypophthalmichthys molitrix. Biol Conserv 183:77-84. doi:10.1016/j.biocon.2014.11. 020

Lacoursière-Roussel A, Côté G, Leclerc V, Bernatchez L (2016) Quantifying relative fish abundance with eDNA: a promising tool for fisheries management. J Appl Ecol 53:1148-1157. doi:10.1111/1365-2664.12598

Maruyama A, Nakamura K, Yamanaka H, Kondoh M, Minamoto T (2014) The release rate of environmental DNA from juvenile and adult fish. PLoS One 9:e114639. doi:10.1371/journal.pone. 0114639

Minamoto T, Naka T, Moji K, Maruyama A (2016) Techniques for the practical collection of environmental DNA: filter selection, preservation, and extraction. Limnol 17:23-32. doi:10.1007/ s10201-015-0457-4

Miya M, Sato Y, Fukunaga T, Sado T, Poulsen JY, Sato K, Minamoto T, Yamamoto S, Yamanaka H, Araki H, Kondoh M, Iwasaki W (2015) MiFish, a set of universal PCR primers for metabarcoding environmental DNA from fishes: detection of more than 230 subtropical marine species. R Soc Open Sci 2:150088. doi:10. 1098/rsos. 150088

Pilliod DS, Goldberg CS, Arkle RS, Waits LP (2014) Factors influencing detection of eDNA from a stream-dwelling amphibian. Mol Ecol Resour 14:109-116. doi:10.1139/cjfas-2013-0047

Rees HC, Maddison BC, Middleditch DJ, Patmore JRM, Gough KC, Crispo E (2014) The detection of aquatic animal species using environmental DNA-a review of eDNA as a survey tool in ecology. J Appl Ecol 51:1450-1459. doi:10.1111/1365-2664.12306

Renshaw MA, Olds BP, Jerde CL, McVeigh MM, Lodge DM (2015) The room temperature preservation of filtered environmental DNA samples and assimilation into a phenol-chloroformisoamyl alcohol DNA extraction. Mol Ecol Resour 15:168-176. doi:10.1111/1755-0998.12281

Takahara T, Minamoto T, Yamanaka H, Doi H, Kawabata Z (2012) Estimation of fish biomass using environmental DNA. PLoS One 7:e35868. doi:10.1371/journal.pone.0035868

Takahara T, Minamoto T, Doi H (2013) Using environmental DNA to estimate the distribution of an invasive fish species in ponds. PLoS One 8:e56584. doi:10.1371/journal.pone.0056584

Takahara T, Minamoto T, Doi H (2015) Effects of sample processing on the detection rate of environmental DNA from the Common carp (Cyprinus carpio). Biol Conserv 183:64-69. doi:10.1016/j. biocon.2014.11.014

Thomsen PF, Kielgast J, Iversen LL, Møller PR, Rasmussen M, Willerslev E (2012) Detection of a diverse marine fish fauna using environmental DNA from seawater samples. PLoS One 7:e41732. doi:10.1371/journal.pone.0041732

Yamanaka H, Minamoto T (2016) The use of environmental DNA of fishes as an efficient method of determining habitat connectivity. Ecol Indic 62:147-153. doi:10.1016/j.ecolind.2015.11.022

Ziani K, Chang Y, McLandsborough L, McClements DJ (2011) Influence of surfactant charge on antimicrobial efficacy of surfactant-stabilized thyme oil nanoemulsions. J Agric Food Chem 59:6247-6255. doi:10.1021/jf200450m 